Journal of Qualitative Criminal Justice \& Criminology • 2020 | Volume 9, Issue 1

\title{
Explaining the Body-Worn Camera Perspective Bias
}

Rémi Boivin ${ }^{1}$, Camille Faubert ${ }^{2}$, Annie Gendron ${ }^{3}$, Bruno Poulin ${ }^{4}$

${ }^{1}$ Université de Montréal and International Centre for Comparative Criminology,

2Université de Montréal,

${ }^{3}$ École Nationale de Police du Québec and International Centre for Comparative Criminology,

4 École Nationale de Police du Québec

Published on: Nov 09, 2020

Updated on: Nov 06, 2020

DOI: $10.21428 / 88 d e 04 a 1 . b c 4 f d e d a$

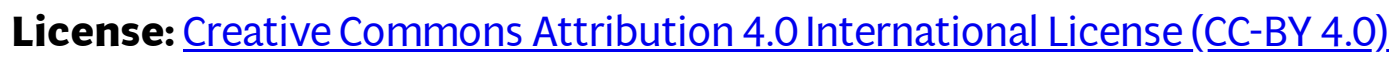




\begin{abstract}
Body-worn cameras (BWCs) can be used to provide video evidence that is expected to help settle cases quickly. The present study explores the assumption that everyone who watches a recorded intervention will have the same understanding of the images. Focus groups were conducted with different people: citizens from the general population, in-training police candidates and cadets, as well as experienced police officers. The aim was to provide insights into how a potential BWC perspective bias affects attitudes towards use of force incidents. Results suggest that the bias has more effect on those without actual experience of police work. In particular, it appears that BWC's first-person perspective encourages self-imagery but that only experienced officers and, to a lesser extent, intraining police candidates can put themselves in a situation similar to that in the video. Also, while distance is recognized as a crucial element in threat assessment, unexperienced participants noted that it was difficult to estimate distance from the BWC footage.
\end{abstract}

\title{
Introduction
}

Using body-worn cameras (BWCs) to capture and record police encounters from the point of view of intervening officers has quickly become routine. Their first documented use was in the United Kingdom in 2005-06 (Goodall, 2007; Spencer \& Cheshire, 2017). Less than ten years later, they were being used in organizations throughout the world, first as part of relatively small-scale pilot studies (e.g., Ariel et al., 2013; Edmonton Police Service, 2015) and then as routine in a significant number of police agencies. For example, in 2013, almost a third of local US police departments reported that they used BWCs (Reaves, 2015). While early studies suggested that their use had a major impact on the behavior of citizens and officers, more recent studies have tempered this argument. For example, Ariel et al. (2016b) conducted a study on the impact of BWCs on police use of force in 10 European countries and concluded that there was no evidence for a deterrent effect. As a consequence, suppliers now appear to focus their sales pitch on the use of BWCs to record evidence and argue that they provide video evidence that should help settle cases quickly, despite limited empirical evidence (see Ellis et al. (2015), Grossmith et al. (2015) and Morrow et al. (2016) for exceptions).

This line of argument concerns not the camera itself, but the footage it provides: BWCs can be used to "fact-check" police interactions. After all, a BWC is a device designed to provide a "first-person" perspective on interventions and create a potentially permanent digital video recording of police encounters. As such, BWCs are often assumed to provide watchers (e.g., judges, jurors, police officers, members of the public) an objective and complete record of interventions. Furthermore, prosecutors believe that video evidence, in general, is strong (e.g., Frederick \& Stemen, 2012) and studies found that prosecutors make more punitive charges when such evidence is available (e.g., Kutateladze et al., 2015). There is a vast social psychology literature on the effect of camera angles on perception and a 
great deal of marketing research in the same area. However, there are almost no corresponding studies on BWCs. The only exception-Boivin et al. (2017) - suggests that there might be a perspective bias related to the particular "first-person" perspective provided by BWCs, meaning that images may not "speak for themselves." The results of that study are concerning because, contrary to what is widely believed, BWCs may not provide a complete and objective view of controversial interventions. More research is needed, in part because the experimental and quantitative design of Boivin et al.'s (2017) study prevented it from providing a detailed explanation of the underlying process which could explain the BWC perspective bias. Also, Boivin et al. (2017) found a perspective bias with police candidates (in-training, without prior experience of the job) but not with university students. Experienced police officers with first-hand knowledge of the job and directly involved in the current BWC debate were not surveyed. The present study seeks to contrast the points of view of this latter group of experienced officers with those of less experienced (i.e., police candidates and cadets) and less involved (i.e., university students and citizens) in order to get a well-rounded understanding of the mechanisms underlying the BWC perspective bias. This would provide insights into who is affected by this bias and its effect on their attitudes. In short, the present study challenges the assumption that everyone who watches a recorded intervention will have the same understanding of the images.

\section{Body-worn cameras in theory}

The use of body-worn cameras is supported by a vast majority of people, although their reasons differ (Sousa et al., 2018). Citizens and politicians, for their part, see it as a tool to increase police accountability and transparency, improve the quality of interventions as well as raise citizens' perceptions of police legitimacy (Crow et al., 2016; Sousa et al., 2017). For example, in 2015, the Obama administration responded to several deadly and highly controversial altercations between police and unarmed citizens and introduced a granting program to help American police departments buy BWCs. Sousa et al. (2017) observed that, in their sample of 599 American citizens, 91\% believed that BWCs would increase police transparency, $66 \%$ thought they would contribute to improving police-citizen relationships, $61 \%$ believed they would increase trust in the police, and $80 \%$ thought BWCs would reduce police use of excessive force. Thus, BWCs are believed to act as a general deterrent on the behavior of those involved in police interventions - both officers and citizens-because they encourage self-awareness and evaluation of the social desirability of the actions being carried out (see also Crow et al., 2016; Henstock and Ariel, 2017; White et al., 2016). Therefore, a BWC is expected to influence police officers to behave in accordance with professional norms and citizens to comply with orders given by the police (Ariel et al., 2017a; White et al., 2017).

Aside from beliefs, some studies have directly assessed how BWCs impact behaviors of police and citizens'. Regarding the behavior of police officers, the current evidence seems contradictory. On the one hand, some empirical studies have found that officers carrying a BWC report fewer incidents of police use-of-force (Ariel et al. 2015; Henstock \& Ariel 2017; Jennings et al. 2015) and more proactive 
activities such as giving citations and initiating encounters (Ready \& Young 2015). On the other hand, in the 10 European countries studied by Ariel et al. (2016b), no deterrent effect of BWCs was observed on incidents of police use of force, and Hedberg et al. (2017) noticed that BWCs had no impact on the volume of arrest officers made. The evidence seems more promising for citizens' compliance with the police: 1) BWCs may be seen as increasing the risk (or perception of risk) of apprehension and conviction, leading potential rule-breakers to avoid criminal actions (Ariel et al., 2017a), and 2), according to theories of police effectiveness and police legitimacy, BWCs seem to stimulate citizens' cooperation with the police and "increase people's willingness to report crimes to the police" (Ariel 2016: 351).

In addition to the arguments in favor of BWCs from citizens and politicians, many police officers (patrol and specialized units) favor BWCs because they expect them to provide thorough evidence as well as some protection against unfounded complaints or physical assaults (Gaub et al., 2017; Gaub et al., 2016; Jennings et al., 2014). A few studies have found that officers wearing BWCs are indeed the subject of fewer citizen/external complaints (Ariel et al., 2017b; Grossmith et al., 2015; Hedberg et al., 2017; Jennings et al. 2015; Katz et al. 2015). Ariel et al. (2017b) explain that BWCs seem to increase perceptions of police procedural justice and, consequently, police legitimacy and perceptions of police performance; this more favorable image of the police is associated with fewer complaints. As stated by Harris (2010: 364):

If citizens can see that they were perhaps mistaken, that they did not understand the situation from the officer's point of view, or that they did not have all the facts, they may come away with a better grasp of the situation and not continue with the complaint process.

While important, these studies focus on the BWC as an object and on how the presence of this objectand the expectations for its use - may affect behavior (Young \& Ready, 2016). In other words, the question of whether the camera is actually recording has little effect on the results of these studies. In such a context, an important feature of BWCs is neglected: its ability to document interventions a posteriori, making it possible to assess their quality and to determine the truth about allegations of wrongful behavior, either of police officers or citizens. Recent reviews of the literature show that comparatively little is known about how BWC footage affects the assessment of police intervention by courts and, more generally, by the public (e.g., Lum et al., 2019; White, 2014). One rare exception is the study by Morrow et al. (2016) on domestic violence cases that found that cases with BWC footage were "more likely to result in an arrest, have charges filed, have cases furthered, result in a guilty plea, and result in a guilty verdict at trial" (p.303). Thus, their study suggests that BWCs provide valuable evidence for police officers, lawyers, defendants, and judges. Relatedly, Culhane and colleagues (2016, 2018) wondered whether footage from BWCs could alter citizens' views of police interventions. Based on samples of American citizens (of respectively 404 participants for Culhane et al. (2016) and 215 
participants for Culhane and Schweitzer (2018)ํ), they observed that those who were randomly assigned to view footage from a BWC of a police use-of-force incident or to listen the soundtrack considered the intervention more justified than those who read the transcript of this same intervention. Viewing the BWC footage was associated with a significant 1.12 unit increase of the perception of justifiability of the officer's use-of-force in the situation under study. Therefore, the footage from BWCs influenced the assessment of police use-of-force made by the public which brought Culhane et al. (2016: 266) to conclude that "[p]olice departments should adopt BWC technology to aid in legal proceedings after a police use of force event has occurred."

In this context, it is largely assumed that the videos provided by BWCs are unedited and "speak for themselves," i.e., that everyone who watches a recorded intervention will have the same understanding of the images since the video gives an objective proof of reality (Brucato, 2015). In cognitive psychology, this assumption is labeled "naïve realism" (Morrison 2017). To put it another way, it is assumed that anyone who watches the evidence would reach a similar decision. Such an assumption has, however, often been challenged in other fields. One of the most careful analyses is based on the case of Scott v. Harris (2007), in which a car chase ended with a police vehicle ramming the suspect's car, causing it to crash and leaving the suspect permanently paralyzed from the neck down. The suspect sued the officer, arguing that he had not been a significant threat to pedestrians and other motorists, and thus that the maneuver (the ramming) was associated with unreasonable risks of serious injury or death to himself. Footage of the car chase and crash was obtained from the dashboard camera of the police car (available on various video-sharing websites). Based largely on this recording, both the District Court and the Court of Appeal decided in favor of the complainant, concluding that the police officer's maneuver was unreasonable. However, using the same evidence, the Supreme Court overturned the previous decisions and decided in favor of the officer, ruling that the complainant was a threat to others and, thus, that the maneuver was reasonable. In short, judges from different courts saw the same video of a police intervention but interpreted it in completely different ways. Kahan et al. (2009) used this case to investigate attitudes towards controversial police interventions. They showed the video of the car chase to 1,350 research participants and asked them to rate their agreement with a number of related statements such as, during the pursuit, the motorist drove in a manner that put members of the public and/or the police at great risk of death." They found that while most respondents agreed with the Supreme Court's position, a significant percentage of respondents disagreed, holding opinions more in line with the first court decisions, demonstrating again that there were major disagreements among people looking at the same video. Most importantly, they found systematic differences among identifiable sub-groups (e.g., African Americans, low-income workers, residents of the Northeast). As Kahan et al. (2009) note, "reactions to the Scott tape [were] shaped by various sources of value-motivated cognition" (p. 42). Not only did the video not speak for itself, but individual characteristics were systematically associated with specific perceptions. 


\section{The camera perspective bias}

Other researchers have investigated the possibility that a single scene shown from different points of view may be interpreted differently by the same individual, suggesting that opinions may be altered simply by changing the way a scene is presented. Brucato (2015, p. 456) expresses this idea in a rather eloquent way: "In an environment in which cameras are nearly ubiquitous and increasingly mobile, crucial is the perspective from which documentation is captured." The discovery of a "camera perspective bias" in criminal justice is usually attributed to Lassiter and Irvine (1986), who filmed a recreation of an interrogation from three points of view and asked participants to rate the level of coercion/voluntariness of the depicted confession. After randomly attributing one of the three points of view to their participants, they found that respondents who viewed the version that focused on the suspect (the suspect was recorded by a camera behind the detective's shoulder) reported a lower level of coercion than those who saw the interrogation from other perspectives (a focus on the detective and an equal focus on both subject and detective). They concluded that "the point of view from which a confession is videotaped can have a considerable impact on observers' judgments of whether that confession was voluntary or coerced" (Lassiter \& Irvine 1986: 272). A considerable amount of empirical research has confirmed the existence of a camera perspective bias in evaluating criminal cases (e.g., Landstrom et al. 2007; Lassiter et al. 1992; Lassiter et al. 2007; Park \& Pyo 2012). The bias appears to hold even when participants are instructed to focus on the content of the interrogation and confession (Lassiter et al. 2002) and when the video evidence is shown to experienced judges and law enforcement experts (Lassiter et al. 2007).

Landström and Granhag (2008) argued that, in addition to the point of view provided by the video, the camera shot (i.e.. the distance between the camera and the event being filmed) must be considered. To test this hypothesis, they randomly allocated their 256 participants to view the video of a child's confession recording from one of four experimental conditions: 1) focus on the child only from a 1meter distance, 2) focus on the child only from a 2-meter distance, 3) focus on the child and the interviewer from a 2-meter distance, and 4) focus on the child and the interviewer from a 7-meter distance. The group who viewed this latter video-that portrayed the child and the interviewer from a 7-meter distance-thought the child looked more relaxed and natural. Those who viewed the child from closer (1 meter) had a higher tendency to perceive that the child was thinking hard to remember details of his testimony. By comparing variations in point of view and distance separately, Landström and Granhag (2008) explain differences in perceptions of a child's testimony solely because of variations in the distance between the camera and its subject; therefore, "closer shots create less favourable impression of the target than longer shots (p. 392), probably because the former allows for participants to detect subtle facial movements that entail nervousness (Landström \& Granhag, 2008). Such results raise questions about the belief that videos are infallible in their representation of reality. Even if this idea is accepted, which version of the video shows "the truth," Kahan et al. (2009) 
showed that different individuals had different understandings of the same video; Lassiter and colleagues, as well as Landström and colleagues, showed that one individual could have different understandings of a situation depending on how the video was filmed.

Very few studies have transposed this phenomenon to BWCs. Turner et al. (2019) surveyed 279 participants online using different videos of police interventions in order to compare the perceptions evoked by BWCs and dash cams. The authors observed that their participants who saw the BWC footage perceived lower intention of wrongdoing by the officer and lower ratings of blame. They explain this result by saying that BWC footage has no visual salience of the police officer who wears it, which is associated with lower perceptions of intentionality. They conclude that: "If the difference between [BWC] and dashcam footage is interpreted as bias on the part of [BWC], this research suggests that viewing $[\mathrm{BWC}]$ footage might make judgments by jurors and as well by the general public more lenient toward the [BWC] wearer (usually a police officer) than might otherwise be warranted (p. 1204)."

Boivin et al. (2017) similarly investigated a perspective bias related to BWCs. They showed footage from a staged police intervention, during which lethal force was used by the police against a threatening individual, to 400 participants, approximately half of whom were university students and half police candidates. They then asked participants to report their level of agreement or disagreement with the intervention, using 4-point scales. Participants did not know that there were two versions of the scene - one provided by a surveillance camera located in the upper corner of the room and one from the BWC worn by the officer who was shown using a firearm. Participants were randomly shown only one of the two versions. While a camera perspective bias was not found among university students, Boivin et al. found that police cadets who saw the intervention filmed through a BWC were more likely to have negative opinions about it than police cadets who viewed the surveillance camera footage. Their results suggest, contrary to their expectations, that the more involved in the police community individuals are, the more affected they are by the camera perspective on these interventions. They conclude that "viewers - such as trained police cadets - [who] have the tools to analyze a situation ... might react more 'coldly' to images of controversial interventions and consider various elements before providing their opinion" (p. 137). Because they did not survey individuals with experience in law enforcement (e.g., police officers, prosecutors), the data did not allow Boivin et al. (2017) to directly test this hypothesis, but their results suggest that a major reassessment of the assumption that cameras "speak for themselves" is needed. An explanation of the more negative opinions of police candidates on interventions from the BWC point of view compared to closed-circuit television (CCTV) is also important if, for example, video footage is to be used as evidence in court.

The impact of photographic evidence on juror verdict has been studied for decades, with researchers routinely finding that it has significant effects on various culpability measures. For example, Bright \& Goodman-Delahunty (2006) found that less than 10\% of mock jurors who were presented verbal 
evidence voted to convict while the corresponding proportion of those who saw photographic evidence was over 40\%. Similarly, in Martin et al.'s (2007) study conducted in Catalonia, Spain, after random allocation of participants into one of the two experimental conditions, those who were presented criminal evidence in video format - which is considered a "more realistic media" (p. 149) - had 1.85 times more chances of reaching a guilty verdict than those who read a transcript of the events. Precisely, the authors determined that their participants who viewed video evidence were less likely to perceive that, in the cases presented, the defendants surrendered peacefully to the police, and they were more likely to believe that the defendants were in the victim's home, that they knew the victim was vulnerable, and that their beating of the victim contributed to her death. The authors hypothesize that video evidence, being more realistic, gives a better perception and understanding of events, prompts greater involvement from people, and triggers more emotions, which weighs heavier in the decision-making regarding a criminal verdict. The impact of video evidence from BWC on court decisions has not yet been empirically studied (for cautionary remarks on the use of video evidence, see Granot et al., 2017). However, solid evidence seems to point to the fact that BWCs are particularly prone to perspective bias, which should grant caution to the tendency to resort to their footage blindly in court.

\section{The BWC perspective bias}

According to past research, several features of BWCs may be associated with perspective biases. First, Boivin et al. (2017) found suggestive evidence linking distance perception and point of view: police candidates who watched footage from the BWC were significantly more likely to report that the officer fired too early, suggesting that some participants saw the distance between the officer and the subject as greater in the BWC footage than in footage from the surveillance camera. This finding may be related to the fact that many body cameras, unlike surveillance cameras, are equipped with fisheye" lenses that provide a wide-angle panoramic field of view of up to 170 degrees in all directions, which is considerably larger than that provided by the average human eye, especially in terms of peripheral vision (Strasburger et al. 2011). Suppliers market this feature as a way to capture more of what you see" (Axon's Body 2) and to record both the actions of the wearer and those in its field of view" (Vievu's LE3). However, it may be problematic because fisheye lenses achieve their wide-angle view by creating a hemispheric projection" of the environment that produces a convex non-rectilinear image that cannot be understood on ordinary geometric principles (Schwalbe et al. 2009; Steyn 1980). In other words, a lens of this kind creates enormous distortion and the estimation of distance is consequently much more difficult (Kingslake 1989). Distance and time are recognized to be crucial elements in threat assessment-as exemplified in the "21-foot rule" (Sandel et al., 2020; Tueller, 2004 (1983)) - and BWCs are widely believed to be a neutral tool for this assessment. To help achieve this, recent models of BWCs are equipped with "regular" lenses that eliminate fisheye distortion. The video that was shown to participants in the Boivin et al. (2017) study had been filmed with the least 
distorting lens available, and yet police candidates saw the assailant as further away in the BWC footage, suggesting that distance perception remains an issue for BWC regardless of the type of lens used.

Second, BWCs provide a first-person perspective that necessarily focuses on the subject of the intervention and his/her immediate environment. Using extensive research in social psychology, Lassiter and colleagues argue that camera perspective bias results from the tendency to ascribe unwarranted causality to a stimulus because it is more salient or noticeable than other available stimuli (McArthur, 1980). They suggest that suspect-focused videotaped confessions led people to judge that the confessions were more voluntary than those shown from other points of view simply because the suspect was more visible (Lassiter et al. 2002). In other words, the camera perspective influences what is the most visually salient aspect of the video and, therefore, the information that is extracted (see also Lassiter et al. (2002), Ratcliff et al. (2006) and Ware et al. (2008)). While this could be advantageous for police officers if subjects appear threatening, some observers highlight that "eyes are not cams" (Phillips, 2016). If BWCs capture more than what was seen by the officer on the scene, reviewers of the footage have two advantages: 1 ) they can watch (often ad nauseam) and analyze interventions in hindsight, without the stress and pressure that affect officers during the action, but also 2) they can notice and integrate into their own analysis elements that were not considered in the initial decision-making.

Relatedly, it is likely that BWC footage neglects significant contextual and situational elements that do not appear in the field of vision of the BWC-for example, the presence of bystanders behind the officer or anything else outside of the police officer's field of view (Grady et al. 2016). As mentioned by Babin et al. (2017: 3): "The video may not have captured enough of the scene to put the event in context (e.g., shadows, sudden movements out of the field of view)." Morrison (2017) explains that, related to incomplete or acontextual video evidence, "viewers are more likely to fill in the blanks with their own subjective world view", which biases their interpretations of the unfolding of events. While experienced judges and law enforcement experts place great value on video evidence (Baker, 2004), BWCs may not be able to provide a full picture of the intervention and, in particular, do not provide a complete understanding of the officer's decision-making process.

Finally, BWCs first-person perspective may encourage self-imagery, especially for individuals better able to relate to the officer wearing the camera. Self-imagery is the process of forming a mental image to reconstruct events that occurred in the past and allow reflection on their unfolding (Jiang et al., 2014; see Morrison (2017) for an explanation of "identification bias"). In marketing research, one goal is to give consumers an experience that allows them to acquire information about a product. Past research has shown that a crucial element in such experiences is how much is incorporated into the imagery: consumers using self-imagery provide higher evaluations of a product than others because 
they imagine themselves with the product (Dahl \& Hoeffler, 2004). Therefore, it could be expected that individuals watching footage from a BWC are better able to imagine themselves undertaking the intervention and that some individuals (e.g., police officers) are particularly likely to relate to the event. "So the first-person perspective in body camera video," Morrison (2017, p. 817) says, "is likely to foster the closest identification possible with the on-screen protagonist, the police officer." Selfimagery could explain the result of Boivin et al. (2017) that a perspective bias was observed for police candidates but not for university students. It can be hypothesized that, due to training, police candidates are better able to form a mental image of the events, understand their unfolding and imagine themselves in the situation.

\section{Current study}

This study investigates further the existence of a camera perspective bias related to BWCs. Previous studies (Turner et al., 2019; Boivin et al., 2017) were based on samples from the general population and university students; Boivin et al. (2017) also surveyed, in addition to university students, police candidates who were undergoing initial training in the Police Academy but had not yet experienced the job on the street. In this context, this study attempts to cover a larger portion of the continuum between untrained (i.e. general population) and experienced individuals by adding the points of view of experienced officers who are well versed in law enforcement. Participants were shown a controversial police intervention showing an officer discharging his firearm towards a mentally unstable man threatening the officers with a baseball bat filmed from two points of view. They were asked to discuss their view of the intervention after seeing the first version-filmed from a surveillance camera-and then asked whether their opinion changed after watching footage from a BWC. The present study goes beyond simple observation and considers past research in social psychology, marketing, and cognitive psychology that suggests that BWCs may be associated with systematic differences due to the particular point of view they provide. Because of the exploratory nature of this study, a qualitative method-focus groups-was used.

\section{Method}

To generate information about the opinions of different groups (Gill et al., 2008), a total of ten focus groups were conducted in various settings (a community center, meeting rooms at the university, a police station, classes in colleges). Focus groups have made their way into mainstream research in the mid-1980 and their main interest lies in the interaction between participants they trigger (Kitzinger, 1995, 1994; Morgan, 1996). Indeed, "[w] hat makes the discussion in focus groups more than the sum of separate individual interviews is the fact that the participants both query each other and explain themselves to each other." (Morgan, 1996, p. 139). Our aim was to grasp the level of agreement and disagreement with the different arguments regarding the BWC perspective bias; generating debate, in the context of focus groups, was, therefore, the most appropriate approach. In the context of this 
research, interactions between participants were a way to spark debate and generate varieties of points of view on the police interventions presented. In addition, since the goal of this study was to explain the results observed by Boivin et al. (2017), focus group was the preferred method because it is known to be efficient in providing explanations to the results of surveys (Kitzinger, 1995, 1994; Morgan, 1996). Lastly, focus groups were appropriate for addressing our research questions since they reveal the participants' attitudes and framework of understanding and provide insight into group norms (Kitzinger, 1995, 1994). This argument makes focus groups relevant for our research since the police are known for having a distinctive subculture associated with specific norms and practices (Paoline \& Terrill, 2014; Paoline, 2004, 2003).

The research took place in the province of Quebec (Canada); all discussions were conducted in French. The authors translated quotations for inclusion in this article. As commonly done in focus group research, this paper is based on a purposive sample (Morgan, 1997): participants were found through announcements made during classes, posts on the Facebook page of the authors' research center, posters displayed on notice boards, and personal contact. We were confronted with some disagreements in the literature regarding the optimal number of participants in a focus group: Kitzinger (1995) suggests between four and eight, but Morgan (1997) advises six to ten. In agreement with both these authors, we aimed to recruit between six and eight participants for each focus group; eight invitations were sent for each group, and last-minute cancellations were not replaced. We were informed minutes prior to group discussion 10 that two groups of officers would have to be combined because of scheduling conflicts, leading to a higher number of participants in this group. Discussions lasted approximately 80 minutes, with group 10 taking slightly longer, presumably because of the number of participants. All participants, except police officers and candidates, were paid 40\$CAN for their participation.

Participants with various characteristics were approached so that groups would be formed according to the degree of experience with law enforcement in Quebec. The first group of participants was composed of school bus drivers without a background in law, criminology, or security $(n=4$ participants). Two groups involved university students, who could be expected to have some theoretical knowledge about the law and/or policing since many of them were graduate students in criminology ( $\mathrm{n}=16$ participants). Individuals in these three groups (school bus drivers and university students) had little personal experience with the police-except for having been given speeding tickets - and were never trained to be police officers. Police candidates-students in police technology training - made up three groups ( $\mathrm{n}=20$ participants). Two groups of police cadets - who had completed the first phase of the initial police training - were met with at the Academy ( $n=13$ participants). Finally, discussions were conducted with two groups of officers who had several years of experience in police work ( $\mathrm{n}=25$ participants). Separating the participants according to their level of experience with law enforcement respects the principle of segmentation in focus group research that 
suggests building homogenous groups; this homogeneity between participants makes discussions more fluid since participants feel they have common traits with others in the group (Morgan, 1996). Morgan (1997: 37) states that such segmentation is justified when the participants "occupy different social roles with regard to a topic," which is the case here. It must also be noted that participants from all the groups except the university students knew each other prior to the focus group; for the university students' groups, some knew each other previously while others met at the focus group meeting.

After a brief presentation of the project by the host (nine groups were conducted by the first author and one by the second), participants were shown video depictions of fictitious but controversial police interventions during which force was used. The videos showed two scenes of takedowns without apparent injury as well as one in which there was a discharge of a firearm with an apparent serious injury to the subject (the man falls to the ground and stops talking). In all cases, participants were invited to discuss their opinions of the intervention they had just watched, starting with a directed question: "In the context presented in the video, the intervention was excellent, satisfactory, questionable, or blameworthy". Procedure was standardized for the ten focus groups in order to make responses comparable (Morgan, 1996).

The current paper focuses on the scene in which a firearm was discharged, filmed from two points of view (BWC and surveillance camera). The 35 -second videos showed two police officers, called by a woman on-site, intervening with a man showing signs of a mental health crisis. After a few seconds, the man stands up, hits a television set with a baseball bat, and then turns to the officers, holding the baseball bat in the air in an obviously threatening manner; the intervention ends when one of the officers discharges his firearm. Both videos were filmed separately (following strict guidelines) so that the BWC was not visible in the video from the surveillance camera (video A). After discussing video A, participants were shown the footage from BWC (video B) and asked if their opinion of the intervention had changed.

\section{Analytical strategy}

In eight cases, focus groups were filmed and then transcribed verbatim. Officers in both groups 9 and 10 expressed reservations about having the discussions recorded, so the second and third authors took notes, respectively, while another author was leading the group. Transcriptions and notes were then coded and analyzed using QDA Miner 4.1.27. As is usual, discussions were first analysed separately (vertical analysis) to identify main themes and then analysed together (horizontal analysis). Since only explicitly mentioned attitudes and perceptions were coded, multiple coders were not necessary for this analysis. Precisely, since we did not seek to interpret or extrapolate latent traits in our participants and focused on the content they clearly expressed, just one coder was deemed reliable. After completing the vertical analysis of discussions, three categories of respondents stood out: the 
general population (including community members and university students), neophytes (police candidates and police cadets), and experienced police officers. Table 1, below, describes the sample of the study.

Table 1. Description of sample

\begin{tabular}{|l|l|l|l|l|}
\hline Focus group & Participants & $\begin{array}{l}\text { Number of } \\
\text { participants }\end{array}$ & $\begin{array}{l}\text { Sociodemographic } \\
\text { characteristics }\end{array}$ & Category \\
\hline 1 & School bus drivers & 4 & 4 males & $\begin{array}{l}\text { General population } \\
(\mathrm{n}=20)\end{array}$ \\
\hline 2 & University students & 8 & 3 males, 5 females & \\
\hline 3 & University students & 8 & 3 males, 5 females & \\
\hline 4 & Police candidates & 9 & 7 males, 2 females & Neophytes (n=35) \\
\hline
\end{tabular}

\section{Results}

\section{Surveillance camera view: Polarization of perceptions}

After participants were shown version A (surveillance camera), they were asked to discuss their general understanding of the intervention. Differences between groups were obvious and predicted subsequent reactions to the BWC footage. Interestingly, participants in groups from the general population and groups with more experience with the police quickly agreed on a collective position: general population groups disagreed with the intervention, while experienced groups believed it was an adequate response to the immediate situation. Neophytes, who, by definition, are in the process of learning a new profession, took more time to come to a general position, and when they reached one, it was a negotiated solution. In other words, the "storming" phase-during which strong differences are expressed-lasted considerably longer for neophytes than for other groups (Finch \& Lewis, 2003). Typically, one individual would express an initial negative position towards the intervention shown, and 2 or 3 other participants would strongly challenge this position. This process was not seen in the general population and experienced groups, where one individual expressed an initial position and fellow participants then gave arguments supporting this position.

There were other differences between neophytes and experienced groups. For example, one of the participants in a group of neophytes summarized a general impression as: "the vision a police officer has is different than ours" (Participant 4, group 6-neophytes). This suggests that neophytes are aware of their lack of experience. Experienced groups commented similarly: 
We should expect individual differences: experience validates your own capacities but also improves the swiftness of your initial assessment of situations. The only person able to decide what should and could be done is the officer leading the intervention. (Participant 2, group 10experienced)

Is it possible that an officer in similar circumstances would not shoot? Certainly. Would I personally deal with the situation otherwise? Probably not. (Participant 7, group 10experienced)

Neophytes never mentioned individual differences. Their arguments carefully followed the Use of Force situational model taught to all students in police technologies starting in their second year. This model focuses on the level of threat perceived by officers and on tactical considerations, such as the presence of weapons. The model implicitly suggests that the elements involved are almost objectivethat videos speak for themselves and that all officers should have a common understanding of them. Experienced participants, especially younger ones, did refer to the model but also acknowledged that the level of threat depended on one's capacities: "they were attacked by a deadly weapon, they could use lethal force. Some officers might try something else, like a Taser, but they were legal [in using a firearm]" (P2, group 9-experienced).

While participants in all categories used similar arguments supporting their position, they were mentioned in a different order - and sometimes with a different meaning. Four main themes emerged: 1) the officer as an individual, 2) reaction time, 3) alternatives, and 4) the level of danger. General population groups granted much more importance to the fact that the intervention unfolded very quickly, although this was generally seen as negative: they criticized the officers for "firing too quickly" (Participant 1, Group 1-general population), for lack of self-control ("they were two and he was alone; it looks like they panicked" (P5, group 2-general population)), and for not trying alternative approaches ("they should have discussed with him, or used another weapon than their gun" (P3, group 3-general population)). However, they eventually recognized that the man was dangerous to others, that the officers had to protect the other civilian in the room, and finally, the officer who fired had to defend himself. In contrast, neophytes and experienced participants mentioned only factors related to the situation and did not specifically criticize the behavior of the officers. They mentioned that "he [the firing officer] had three persons to protect from one individual" (P4, group 5-neophytes), that "the officers had little time to plan their intervention before it took place and they had almost no information to deal with" (P3, group 9-neophytes), and that "the individual had proven that he could be violent by smashing his TV" (P4, group 7-neophytes). A clear difference is that neophytes and experienced participants considered the baseball bat to be "a deadly, long-range weapon" (P5, group 9-neophytes), whereas participants from the general population minimized its danger ("it is not sharp, and cannot even make you bleed" (P5, group 2-general 
population)). Neophytes and experienced participants were also concerned about legal aspects of the intervention as they mentioned that "the officers did not provoke him [the subject of intervention] but tried to protect the woman" (P3, group 6-neophytes) and that "it was the action of the woman that started everything" (P2, group 11-experienced).

All groups devoted some time to suggesting alternatives to shooting into the subject's chest. All general population groups mentioned firing at a leg or arm. In contrast, neophytes and experienced participants mentioned that, while they expected that reaction from the public, such a move was very unlikely because police are trained to aim for the center mass - a target that moves less and that they are more likely to hit, effectively stopping the threat. Another clear difference between the general population and other groups is that they formed a list of options but did not evaluate their practicability. All groups mentioned that a baton, a conducted-energy device (“Taser” or CED), or pepper spray were more acceptable weapons. However, neophytes and experienced considered their use unlikely in these circumstances. Neophytes mentioned situational arguments ("you can't spray inside without becoming intoxicated yourself" (P3, group 6-neophytes)) and concerns about effectiveness ("CED will only work if both electrodes are in contact with the subject, so you need a perfect shot" (P1, group 9-neophytes)) whereas experienced participants mentioned that there was no window of opportunity to use another weapon. All groups then mentioned alternative strategies such as exiting and leaving the man alone in the locked room ("human life is more important than property" (P6, group 5-neophytes)), but neophytes and experienced considered it was an impractical option because the officers had to protect the woman and could not leave the room quickly enough to avoid an attack. It seems that points of view were largely polarized between those involved in the police (neophytes and experienced officers) and the general population. While some overlap in arguments were noticed between neophytes and experienced officers, the opinions of participants from the general population were generally opposite. Table 2 provides a visual breakdown of the general arguments in favor or disfavor of the intervention for the three groups of participants.

Table 2. Visual breakdown of perceptions of the three groups of participants for the intervention filmed with the surveillance camera 


\begin{tabular}{|l|l|l|}
\hline General population & $\begin{array}{l}\text { Find the officer resorted to firearm } \\
\text { too quickly; should have used an } \\
\text { alternative weapon (baton, taser, } \\
\text { pepper spray) }\end{array}$ & $\begin{array}{l}\text { Argue that the officer should have } \\
\text { aimed at leg or arm }\end{array}$ \\
\hline Neophytes & $\begin{array}{l}\text { Minimized the danger of baseball } \\
\text { bat }\end{array}$ & Aware of their lack of experience \\
\hline$+/-$ & $\begin{array}{l}\text { Assessment of intervention based on } \\
\text { teachings from the police training } \\
\text { (i.e., Use of Force situational model) }\end{array}$ \\
\hline
\end{tabular}

\section{The BWC perspective bias}

As noted before, Boivin et al. (2017), using an experimental design in which participants were shown only one version (BWC or surveillance camera) of a controversial police intervention, found a perspective bias related to BWCs for police candidates but not for university students. They extrapolated that the more training individuals have in analyzing police interventions, the more affected they are by the camera perspective on such interventions. Furthermore, participants in their study were more critical of the intervention when seen from the perspective of a BWC. The results of the current research differ in two ways. First, participants from general population groups (including university students) reported a strong BWC perspective bias. In two of the three groups, the first reaction, after seeing video $B$, was that the intervention looked more blameworthy from the BWC perspective; Participants from group 3 (general population) reported that their understanding of the situation - but not their evaluation of it - changed dramatically after watching it from the point of view of the BWC. Second, while neophytes reported a BWC perspective bias, experienced police officers did not, contradicting the hypothesis of Boivin et al. (2017) relating to experience. Both groups reported that the BWC footage confirmed elements suggested in the first version, such as the fact that the officers could not see the baseball bat when they entered the room. The main difference between neophytes and experienced group members was the importance that the former put on their evaluation of distance, while the latter barely mentioned this element in their assessment of the intervention. Consistent with Boivin et al. (2017), neophytes reported that the subject appeared further away when seen from the BWC. 
Two potential explanations suggested by research in other fields appeared particularly relevant. First, both general population and neophyte groups mentioned distance perception as the main element influencing their change in opinion. In all groups but one, the first element mentioned after the BWC footage was shown was that from the BWC point of view, the subject appeared further away. Unsurprisingly, distance was always mentioned in relation to time: because the subject appeared further away, the officer had more time to do something else. But participants were critical of the BWC footage: "The disadvantage of body cameras is that yes, I felt threatened and yes I felt endangered, but is it because of ... the camera itself? You know, the fisheye thing ... I don't know how far he was." (P6, G8-neophytes). Interestingly, general population groups also discussed practical considerationshow the officer could have reacted differently to the attack (e.g., used another weapon) - while neophytes focused largely on tactical possibilities - what could have been done differently to prevent the attack (take the woman out of the room at the beginning, hold her back when the man smashes the TV set).

Second, the first-person perspective of the BWC was appreciated by all groups because it provided a better understanding of the intervention and the officer's decision. The BWC point of view makes it obvious that the officers could not have anticipated the attack because the weapon was concealed, it focuses on the subject's threatening and determined facial expression, and it gives a better idea of the - limited-options available to the officer who fired. BWC footage was considered fairer to the officers and in line with the reasonableness principle (Terrill, 2009). "When you see the body camera, you see the tunnel [limited] vision of the officer, you see the threat, anyone can see it." (P6, G10experienced).

BWC footage was, however, not considered to be perfect. All groups, at some point in the discussions, mentioned that it did not provide a full understanding of the context of intervention, although this was more important for neophytes and experienced. For example, neophytes (group 8) discussed at length how, after watching the BWC footage, they tended to forget that the firing officer had two other lives to protect (these individuals were barely visible during the attack) and that he was stuck in the corner of the room (the door was behind him). These elements were crucial to their assessment of the intervention in the surveillance camera footage as they felt that the officer was aware of them and they might have influenced his decision to fire. Their discussion deviated from the argument that what the camera records may not be perceived by the officer - the "eyes are not cams" argument-to instead take into account what the officer might have considered in his decision-making that was not captured by the BWC. Many participants noted that they did not know how the officers had received the call for help and that this can affect the way officers visualize an upcoming intervention. Table 3 provides a visual breakdown of the results regarding the BWC perspective bias. 
Table 3. Visual breakdown of the presence of a BWC perspective bias for the three groups of participants

\begin{tabular}{|l|l|l|}
\hline Body-worn camera & BWC perspective bias & Arguments \\
\hline General population & Yes & $\begin{array}{l}\text { BWC provides better understanding } \\
\text { of officer's point of view }\end{array}$ \\
\hline Neophytes & Yes & $\begin{array}{l}\text { Evaluation of distance: From the BWC } \\
\text { perspective, the subject looked } \\
\text { further away. Therefore, intervention } \\
\text { looked more blameworthy from BWC } \\
\text { perspective }\end{array}$ \\
\hline Experienced officers & No & $\begin{array}{l}\text { BWC provides a better } \\
\text { understanding of the officer's point } \\
\text { of view but not of the whole context } \\
\text { of the intervention }\end{array}$ \\
\hline & & $\begin{array}{l}\text { No mention of the perception of } \\
\text { distance }\end{array}$ \\
\hline & & \\
\hline
\end{tabular}

\section{Discussion}

Contrary to many studies focusing on police BWCs, this one focused on the footage produced by these devices rather than on the presence of the object. Even though a large proportion of the population seems to think that BWCs will produce quality evidence (Crow et al., 2016), studies start to show that this is not necessarily the case (Boivin et al., 2017). Using studies on the camera perspective bias as a starting point (Landström \& Granhag, 2008; Landström et al., 2007; Lassiter \& Irvine, 1986; Lassiter et al., 2007, 1992; Park \& Pyo, 2012; Turner et al., 2019), this study shows that BWCs, like other types of cameras, generate a perspective bias. Going beyond Boivin et al.'s (2017) conclusions, this study finetunes our understanding of the BWC perspective bias by providing greater details on its occurrence.

Precisely, results show that seeing a police intervention from the BWC perspective affected the general population, neophytes, and experienced police officers very differently. General population participants already had a negative opinion of the intervention before watching it from the BWC point of view. The fact that their negative opinion was confirmed or reinforced by the BWC version may explain why this perspective bias was not captured in the previous experiment by Boivin et al. (2017). Neophytes (police candidates and cadets), in contrast, had a mixed position and thus had latitude to reinforce a more positive or negative opinion. They were learning the police profession and thus were 
open to different opinions. As shown in Table 3, their perceptions seem to be a middle ground between the arguments of the general population and those of experienced officers. Experienced groups were at the other end of the spectrum: they did not denounce the intervention and did not reflect a BWC perspective bias but still recognized that the BWC might have recorded more than what the officer perceived. However, they were not concerned about this fact, stating that "anything can be explained" (P8, G10-experienced). This comment supports the importance of releasing explanations to accompany video depictions of controversial interventions. It also shows that, according to experienced police officers, video accounts of interventions, no matter their quality, should not replace officer testimony.

As explained previously, three features of BWCs are associated with a perspective bias: 1) they alter the perception of distance (Boivin et al., 2017), 2) they provide a first-person perspective (Lassiter et Irvine, 1986; Lassiter et al., 2007, 1992), and 3) they encourage self-imagery (Jiang et al., 2014). Participants in this study tackled these three aspects. Groups from the general population and neophytes expressed that in the footage from the BWC, the subject of the intervention appeared further away. However, perception of distance seems to be linked to the BWC perspective bias only for people who have less experience with the police craft. All groups manifested that BWCs provide a better understanding of the point of view of the shooting officer during the intervention; those involved in the police were, however, less likely to have a biased perception because they recognized that this point of view does not picture the whole context of the intervention.

Lastly, self-imagery is a concept central to marketing research and describes the process of forming a mental image to reconstruct events that occurred in the past and allow reflection on their unfolding (Jiang et al., 2014). In other words, self-imagery refers to the ability to identify with those involved in a video. It turns out that it was an important element in explaining the BWC perspective bias found in the current study. The results of this study indicated that general population groups mentioned several alternatives to the action shown, such as other weapons that could have been used. However, they did not discuss issues related to these uses. Neophytes had such discussions: after mentioning alternatives, participants were quick to discuss how realistic these options were. Their discussion also involved tactical issues, such as what could have been done to prevent the attack. Experienced officers quickly agreed that alternatives were non-existent and did not discuss such possibilities at length, but went further in their analysis and always referred to actual interventions that they or someone they knew had been involved in. The analysis of interventions went from listing practical options without assessment (general population), to listing practical and tactical options with a theoretical assessment (neophytes), to listing largely tactical options with references to past situations (experienced). Experienced officers were better able to put themselves in a situation like that in the video and to ask what they could have done differently, whereas neophytes asked what should have been done according to the theoretical models they had recently learned. It appears that the group most capable 
of self-imagery in this context is the one comprising experienced officers, who seemingly were not affected by the BWC perspective bias. Therefore, self-imagery might be a protector against BWC perspective bias. This is a starting point to understanding who is impacted by the BWC perspective bias but remains concerning in practice since those who make decisions regarding police misconduct (ex: judges and juries) rarely have police experience and are less capable of self-imagery in this kind of context. This demonstration makes the sales pitch of BWCs suppliers about settling cases quickly a lot less convincing. The situation is much more complex than that since, first, BWCs create a biased perspective, and, second, this bias does not affect all viewers equally. So, the images from these cameras do not "speak for themselves," but they speak differently to different groups of people.

\section{Limitations}

Changing the point of view requires a reassessment of distance, and this reassessment, for some unknown reason, always favors the idea that the distance is greater, independent of the point of view. Still, all groups asked to watch the filmed intervention from the surveillance camera point of view more than once and still reported that the subject appeared closer when seen from this perspective. However, participants in all groups (except experienced) noted that it was difficult to estimate distance from the BWC footage, a result that is consistent with previous research (Kingslake, 1989). Further research is needed to investigate the impact of BWC on distance perception.

The method used in the current study may have captured conscious reasons for particular evaluations, while bias related to camera angles and illusory causation are largely unconscious processes. It is possible that focus groups do not capture these unconscious processes because participants were asked to verbalize their emotions/perceptions/opinions and only what was explicitly mentioned was coded for analysis. For example, a more subtle feature of BWCs might influence assessments of police interventions - the fact that it provides a varying vertical angle. Studies in psychology suggest that people may feel more threatened or vulnerable when someone or something rises above them (Van Rompay \& Ludden, 2015). Consequently, when an object is photographed from a low angle (looking up), the viewer judges the object more positively (larger, stronger) than when the same object is photographed from a high angle (Meyers-Levy \& Peracchio, 1992). Meyers-Levy and Peracchio (1992) found that viewers' judgments at eye-level varied. In other words, they found that changing the bodily orientation (or camera angle) of an image might alter how that image is evaluated. BWCs are associated with changing camera angles and thus may make it difficult to provide a definitive evaluation of the images they capture. For instance, the studies in psychology mentioned above suggest that a subject seen from the BWC of an officer who is lying on the ground or ducking might appear to be more threatening than if the same subject was seen from an eye-level or high angle perspective. Some academics recommend that ideally, all video evidence be recorded from a neutral camera angle (Kassin et al. 2010), but this appears difficult to achieve with BWCs. 
One limitation is associated with the methodology: focus groups, taking place in a social context with six to ten other people, can bring some of the participants to censor themselves when they feel that their perceptions and attitudes differ from those of their colleagues (Kitzinger, 1994). Considering that the subject tackled in these focus groups - police use of force - could have been perceived as sensitive to some of them, readers might be concerned that some participants did not voice their real opinions. We are confident that the segmentation of the participants according to whether they were involved in the police or not prevented censorship from being a real problem in our study. Kitzinger (1994: 112) mentions that: "depending on their composition, groups can sometimes actively facilitate the discussion of otherwise 'taboo' topics because the less inhibited members of the group 'break the ice' for shyer participants or one person's revelation of 'discrediting' information encourages others to disclose."

\section{Conclusion}

The use of body-worn cameras by police officers is a technological advance that is, unusually, supported by most police and non-police (Crow et al., 2017; Jennings et al., 2014; Lum et al., 2019; White et al., 2017). Because the technology is relatively new, this support is based mainly on the deterrent effect expected from the mere presence of the camera during an intervention: citizens are expected to comply more readily with orders, and officers are expected to behave more professionally as a result of the anticipated potential consequences of wrongdoing captured by the BWC (Lum et al., 2015). BWCs also record police interventions, and this footage is expected to reveal the objective truth; as such, it can be used as evidence, although its actual effect is only gradually becoming clear.

The results of the current study confirm the existence of a perspective bias related to BWCs and help understand the extent of this bias. While Boivin et al. (2017) suggest that the perspective bias had more effect on those with experience when analyzing use of force incidents, the current study suggests that the bias has more effect on those without police work experience. Both studies add to the literature that strongly contests the assumption that video evidence "speaks for itself" and provides an objective point of view. This highlights a crucial but unanswered question: are individuals with a strictly theoretical- as opposed to practical-knowledge of police work, as is the case with most prosecutors and judges, affected by a perspective bias? Answering this question is essential if BWC footage is to be used as evidence in courts.

\section{References}

Ariel, B. (2016). Increasing cooperation with the police using body worn cameras. Police Quarterly, 19(3): 326-362.

Ariel, B., Farrar, W.A. \& Sutherland, A. (2015). The effect of police body-worn cameras on use of force and citizens' complaints against the police: A randomized controlled trial. Journal of quantitative 
criminology, 31(3): 509-535.

Ariel, B., Sutherland, A., Henstock, D., Young, J., Drover, P., Sykes, J., Megicks, S. \& Henderson, R. (2016a). Report: increases in police use of force in the presence of body-worn cameras are driven by officer discretion: a protocol-based subgroup analysis of ten randomized experiments. Journal of Experimental Criminology, 12(3): 453-463.

Ariel, B., Sutherland, A., Henstock, D., Young, J., Drover, P., Sykes, J., Megicks, S. \& Henderson, R. (2016b). Wearing body cameras increases assaults against officers and does not reduce police use of force: Results from a global multi-site experiment. European Journal of Criminology, 13(6), 744-755.

Ariel, B., Sutherland, A., Henstock, D., Young, J. \& Sosinski, G. (2017a). The deterrence spectrum: Explaining why police body-worn cameras 'work' or 'backfire' in aggressive police public encounters. Policing: A Journal of Policy and Practice, 12(1): 6-26.

Ariel, B., Sutherland, A., Henstock, D., Young, J., Drover, P., Sykes, J., Megicks, S. \& Henderson, R. (2017b). "Countagious Accountability: A global multisite randomized controlled trial on the effect of police body-worn cameras on citizens' complaints against the police. Criminal Justice and Behavior, 44(2): 293-316.

Babin, S., Koslicki, W., Vogel, R., Contestabile, J., Kohri, K \& Makin, D. (2017). Resilient Communications Project: Body-Worn Camera Perception Study Phase 1 (Report \# AOS017-1302). Department of Homeland Security Science and Technology Directorate, Washington DC.

Baker, W. (2004). The impact of video evidence on modern policing (NIJ grant\# 2001-CK-WX-0157). IACP report to National Institute of Justice.

Boivin, R., Gendron, A., Faubert, C. \& Poulin, B. (2017). The body-worn camera perspective bias. Journal of Experimental Criminology, 13(1): 125-142.

Boivin, R., Gendron, A., Faubert, C. \& Poulin, B. (2017). The malleability of attitudes toward the police: immediate effects of the viewing of police use of force videos. Police Practice and Research, 18(4), 366375.

Brucato, B. (2015). Policing made visible: Mobile technologies and the importance of point of view. Surveillance \& Society, 13(3-4): 455-473.

Crow, M., Snyder, J. A., Crichlow, V. J. \& Smykla, J. O. (2016). Community perceptions of police bodyworn cameras. Criminal Justice and Behavior, 44(4): 589-610. 
Culhane, S. E., Boman, J. H. \& Schweitzer, K. (2016). Public perceptions of the justifiability of police shootings: The role of body cameras in a pre- and post-Ferguson experiment. Police Quarterly, 19(3): 251-274.

Culhane, S. W. \& Schweitzer, K. (2018). Police shootings and body cameras one year post-Ferguson. Policing \& Society, 28(9): 1038-1049.

Dahl, D.W. \& Hoeffler, S. (2004). Visualizing the self: Exploring the potential benefits and drawbacks for new product evaluation. Journal of Product Innovation Management, 21(4): 259-267.

Edmonton Police Service (2015). Body worn video: Considering the evidence. Final report of the Edmonton Police Service body worn video pilot project. Edmonton, Canada.

Ellis, T., Jenkins, T., \& Smith, P. (2015). Evaluation of the Introduction of Personal Issue Body Worn Video Cameras (Operation Hyperion) on the Isle of Wight: Final Report to Hampshire Constabulary. University of Portsmouth: Institute of Criminal Justice Studies.

Finch, H. \& Lewis, J. (2003). Focus groups. In J. Ritchie \& J. Lewis (eds.) Qualitative research practice: A guide for social science students and researchers. London: SAGE Publications, 170-198.

Frederick, B. \& Stemen, D. (2012). Anatomy of discretion: An analysis of prosecutorial decision making. Summary report, Vera Institute of Justice.

Gaub, J. E., Choate, D. E., Todak, N., Katz, C. M. \& White, M.D. (2016). Officer Perceptions of Body-Worn Cameras Before and After Deployment. Police Quarterly, 19(3): 275-302.

Gaub, J. E., Todak, N. \& White, M. D. (2017). Beyond Patrol: Exploring the Perceptions of Police Body-Worn Cameras among Officers in Specialized Units. Technical Report, Arizona State University. Retrieved from https://www.researchgate.net/publication/313971114_Beyond_Patrol_Exploring_the_Perceptions_of_P olice_Body-Worn_Cameras_among_Officers_in_Specialized_Units

Gill, P., Stewart, K., Treasure, E. \& Chadwick, B. (2008). Methods of data collection in qualitative research: interviews and focus groups. British dental journal, 204(6): 291-295.

Goodall, M. (2007). Guidance for the police use of body-worn video devices.

Grady, R. H., Butler, B. J. \& Loftus, E. F. (2016). What should happen after an officer-involved shooting? Memory concerns in police reporting procedures. Journal of Applied Research in Memory and Cognition, 5: $246-251$.

Grossmith, L., Owens, C., Finn, W., Mann, D., Davies, T. \& Baika, L. (2015). Police, camera, evidence: London's cluster randomised controlled trial of Body Worn Video. London: College of Policing and the 
Mayor's Office for Policing and Crime (MOPAC).

Harris, D. A. (2010). Picture this: Body-worn video devices (heads cams) as tools for ensuring fourth amendment compliance by police. Texas Tech Law Review, 43(1): 357-372.

Hedberg, E. C., Katz, C. M. \& Choate, D. E. (2017). Body-worn cameras and citizen interactions with police officers: Estimating plausible effects given varying compliance levels. Justice Quarterly, 34(4): 627-651.

Henstock, D. \& Ariel, B. (2017). Testing the effects of police body-worn cameras on use of force during arrests: A randomised controlled trial in a large British police force. European Journal of Criminology, 14(6): 720-750.

Jennings, W. G., Fridell, L. A. \& Lynch, M. D. (2014). Cops and cameras: Officer perceptions of the use of body-worn cameras in law enforcement. Journal of Criminal Justice, 42(6): 549-556.

Jennings, W. G., Lynch, M. D. \& Fridell, L. A. (2015). Evaluating the impact of police officer body-worn cameras (BWCs) on response-to-resistance and serious external complaints: Evidence from the Orlando police department (OPD) experience utilizing a randomized controlled experiment. Journal of Criminal Justice, 43(6): 480-486.

Jiang, Y., Adaval, R., Steinhart, Y. \& Wyer Jr, R. S. (2014). Imagining yourself in the scene: The interactive effects of goal-driven self-imagery and visual perspectives on consumer behavior. Journal of Consumer Research, 41(2): 418-435.

Kahan, D. M., Hoffman, D. A. \& Braman, D. (2009). Whose eyes are you going to believe? Scott v. Harris and the perils of cognitive illiberalism. Harvard Law Review: 837-906.

Katz, C. M., Kurtenbach, M., Choate, D. E. \& White, M. D. (2015). Phoenix, Arizona, smart policing initiative: evaluating the impact of police officer body-worn cameras. Washington, DC: US Department of Justice, Bureau of Justice Assistance.

Kingslake, R. (1989). A history of the photographic lens: Elsevier.

Kitzinger, J. (1995). Qualitative Research: Introducing focus groups. The BMJ, 311: 1-8.

Kitzinger, J. (1994). The methodology of focus groups: The importance of interaction between research participants. Sociology of Health \& Illness, 16(1): 103-121.

Kutateladze, B.L. Lawson, V.Z. \& Andiloro, N.R. (2015). Does evidence really matter? An exploratory analysis of the role of evidence in plea bargaining in felony drug cases. Law and Human Behavior, 39(5): 431-442. 
Landström, S. \& Granhag, P. A. (2008). Children's truthful and deceptive testimonies: How camera perspective affects adult observers' perception and assessment. Psychology, Crime \& Law, 14(5): 381-396.

Landström, S., Hjelmsäter, A., Roos, E. \& Granhag, P.A. (2007). The camera perspective bias: A case study. Journal of investigative psychology and offender profiling, 4(3): 199-208.

Lassiter, G. D., Beers, M. J., Geers, A. L., Handley, I. M., Munhall, P. J. \& Weiland, P. E. (2002). Further evidence of a robust point-of-view bias in videotaped confessions. Current Psychology, 21(3): 265-288.

Lassiter, D. G., Diamond, S. S., Schmidt, H. C. \& Elek, J. K. (2007). Evaluating videotaped confessions: Expertise provides no defense against the camera-perspective effect. Psychological Science, 18(3): 224226.

Lassiter, G. D., Geers, A. L., Munhall, P. J., Ploutz-Snyder, R. J. \& Breitenbecher, D. L. (2002). Illusory causation: Why it occurs. Psychological Science, 13(4): 299-305.

Lassiter, G. D. \& Irvine, A. A. (1986). Videotaped confessions: The impact of camera point of view on judgments of coercion. Journal of Applied Social Psychology, 16(3): 268-276.

Lassiter, G. D., Slaw, R. D., Briggs, M. A. \& Scanlan, C. R. (1992). The potential for bias in videotaped confessions. Journal of Applied Social Psychology, 22(23): 1838-1851.

Lum, C. M., Koper, C. S., Merola, L. M., Scherer, A. \& Reioux, A. (2015). Existing and ongoing body worn camera research: Knowledge gaps and opportunities: George Mason University.

Lum, C., Stolz, M., Koper, C.S. \& Scherer, J.A. (2019). Research on body-worn cameras: What we know, what we need to know. Criminology \& Public Policy, 18(1), 93-118.

Martin, M. E., De La Fuente, L., De La Fuente, E. I. \& Garcia, J. (2007). The influence of sample type, presentation format and strength of evidence on juror simulation research. Psychology, Crime $\mathcal{E}$ Law, 13(2): 139-153.

Mcarthur, L. Z. (1980). Illusory causation and illusory correlation: Two epistemological accounts. Personality and Social Psychology Bulletin, 6(4), 507-519.

Meyers-Levy, J. \& Peracchio, L. A. (1992). Getting an angle in advertising: The effect of camera angle on product evaluations. Journal of Marketing Research, 29, 454-461.

Morgan, D. L. (1997) Planning and research design for focus groups. In D. L. Morgan (Ed.), Focus Groups as Qualitative Research (pp. 31-45). Thousand Oaks: Sage Publications.

Morgan, D. L. (1996). Focus groups. Annual Review of Sociology, 22: 129-152. 
Morrison, C. (2017). Body camera obscura: The semiotics of police video. American Criminal Law Review, 54(3): 791-842.

Morrow, W.J., Katz, C.M. \& Choate, D.E. (2016). Assessing the impact of police body-worn cameras on arresting, prosecuting, and convicting suspects of intimate partner violence. Police Quarterly, 19(3): 303-325.

Paoline, E. A. (2004). Shedding light on police culture: An examination of officers' occupational attitudes. Police Quarterly, 7(2): 205-236.

Paoline, E. A. (2003). Taking stock: Toward a richer understanding of police culture. Journal of Criminal Justice, 31: 199-214.

Paoline, E. A. \& Terrill, W. (2014). Police Culture: Adapting to the Strains of the Job. Durham, NC: Carolina Academic Press.

Park, K. \& Pyo, J. (2012). An explanation for camera perspective bias in voluntariness judgment for video-recorded confession: Suggestion of cognitive frame. Law and human behavior, 36(3): 184-194.

Phillips, S. W. (2016). Eyes are not cameras: The importance of integrating perceptual distortions, misinformation, and false memories into the police body camera debate. Policing: A Journal of Policy and Practice, 12(1): 91-99.

Ratcliff, J. J., Lassiter, G. D., Schmidt, H. C. \& Snyder, C. J. (2006). Camera perspective bias in videotaped confessions: Experimental evidence of its perceptual basis. Journal of Experimental Psychology: Applied, 12(4): 197-206.

Ready, J. T. \& Young, J. T. (2015). The impact of on-officer video cameras on police-citizen contacts: findings from a controlled experiment in Mesa, AZ. Journal of Experimental Criminology, 11(3): 445-458. Reaves, B. A. (2015). Local police departments, 2013: Equipment and technology: BOJS US Department of Justice.

Sandel, W.L., Martaindale, M.H. \& Blair, J.P. (2020). A scientific examination of the 21-foot rule. Police Practice and Research, DOI: 10.1080/15614263.2020.1772785.

Schwalbe, E., Maas, H.-G., Kenter, M. \& Wagner, S. (2009). Hemispheric image modeling and analysis techniques for solar radiation determination in forest ecosystems. Photogrammetric Engineering $\mathcal{E}$ Remote Sensing, 75(4): 375-384.

Scott vs. Harris 550 US 372 
Sousa, W. H., Miethe, T. D. et Sakiyama, M. (2017). Inconsistencies in public opinion of body-worn cameras on police: Transparency, trust, and improved police-citizen relationships. Policing: A Journal of Policy and Practice, 12(1): 100-108.

Spencer, D. \& Cheschire, R. (2017). Ten years of body worn video in Northamptonshire Police. Policing: A Journal of Policy and Practice, 12(1): 116-119.

Steyn, D. (1980). The calculation of view factors from fisheye-lens photographs: Research note.

Strasburger, H., Rentschler, I. \& Jüttner, M. (2011). Peripheral vision and pattern recognition: A review. Journal of vision, 11(5): 13-13.

Terrill, W. (2009). The elusive nature of reasonableness. Criminology \& Public Policy, 8(1): 163-172.

Tueller, D. (2004). How close is too close? SWAT magazine, March 1983 reprinted.

Turner, B. L., Caruso, E. M., Dilich, M. A \& Roese, N. J. (2019). Body camera footage leads to lower judgments of intent than dash camera footage. Proceedings of the National Academy of Sciences of the United States of America, 116(4): 1201-1206.

Van Rompay, T. \& Ludden, G. (2015). Types of embodiment in design: The embodied foundations of meaning and affect in product design. International journal of design, 9(1): 1-11.

Ware, L. J., Lassiter, G. D., Patterson, S. M. \& Ransom, M. R. (2008). Camera perspective bias in videotaped confessions: Evidence that visual attention is a mediator. Journal of Experimental Psychology: Applied, 14(2), 192.

White, M. D., Gaub, J. E. \& Todak, N. (2017). Exploring the potential for body-worn cameras to reduce violence in police-citizen encounters. Policing: A Journal of Policy and Practice, 12(1): 66-76.

White, M. D., Todak, N. \& Gaub, J. E. (2016). Assessing citizen perceptions of body-worn cameras after encounters with police. Policing: An International Journal of Police Strategies \& Management, 40(4): 689703.

Young, J. T. N. \& Ready, J. (2016). A longitudinal analysis of the relationship between administrative policy, technological preferences, and body-worn camera activation among police officers. Policing: $A$ Journal of Policy and Practice, 12(1): 27-42.

\section{Contributors}

Rémi Boivin has a $\mathrm{PhD}$ in criminology and is Associate Professor at the School of Criminology, Université de Montréal. He is also director of the International Centre for Comparative Criminology. His research interests include decision-making, police use of force and crime analysis. His recent work 
has appeared in the Journal of Quantitative Criminology, the Journal of Experimental Criminology, the Journal of Research in Crime and Delinquency, and Police Quarterly.

Camille Faubert received a PhD in criminology from the University of Montréal, Canada in September 2019. She is currently a postdoctoral fellow at Temple University. Her doctoral dissertation addresses the development of attitudes toward use of force throughout the police initial training using quantitative methods. She has also collaborated on several scholarly publications related to police body worn cameras.

Annie Gendron has a $\mathrm{PhD}$ in psychology and is researcher at the Strategic Research and Development Center, École Nationale de Police du Québec (Police Academy). She is also a regular researcher at the International Centre for Comparative Criminology.

Bruno Poulin has a M.Sc. in Human Kinetics and is use of force expert at the Knowledge and Expertise Centre, École Nationale de Police du Québec (Police Academy).

\section{Footnotes}

1. Results of Culhane and Schweitzer (2018) should be interpreted with caution since, even though means are in the expected direction, differences in justifiability of police use of force between the three experimental conditions (BWC footage, audio recording and transcript) are non-significant. $\subseteq$ 